\title{
Grief, Care, and Play: Theorizing the Affective Roots of the Social Self*
}

\author{
Seth Abrutyn \\ University of British Columbia
}

Omar Lizardo

University of California, Los Angeles

\section{UNCOPYEDITED PREPRINT FORTHCOMING IN ADVANCES IN GROUP PROCESSES}

Running Head: Grief, Care, and Play

* Please direct all correspondence to Seth Abrutyn, University of British Columbia, The Department of Sociology, 6303 NW Marine Drive, Vancouver, BC Canada V6T 1 Z1 or seth.abrutyn@ubc.ca. 


\section{Structured Abstract}

Purpose: For several decades, some sociologists have turned to evolutionary biology, neuroscience, and cognitive science to support, modify, and reconfigure existing social psychological theory. In this paper, we build on this momentum by considering the relevance of recent work in affective and cognitive neuroscience for understanding emotions and the self. Our principal aim is to enlarge the range of phenomena currently considered by sociologists who study emotion, while showing how affective dynamics play an important role across every outcome and process of interests to social scientists.

Approach: Central to our concern is the way in which external social objects become essential to, and emotionally significant for, the self. To that end, we draw on ideas from phenomenology, pragmatism, classic symbolic interactionism, and dramaturgy. We begin by showing how basic affective systems may graft on, build from, and extend current social psychological usages of emotions as well as the important sociological work being done on self, from both symbolic interactionist (SI) and identity theory (IT) perspectives. Subsequently, we turn to the promising directions in studying emotional biographies and various aspects related to embodiment.

Originality of the Paper: Sociologists usually think of emotions as dependent or intervening variables: (a) signaling identity or situational incongruence, (b) states to be managed, and (c) structural dimensions of superordinate-subordinate relationships. Our integration of the theory of affective systems emphasizes the independence (and, often, primacy) emotions have over other functions and suggests how this affects the construction and maintenance of self and social experience.

Implications: The focus on affective systems suggests new research agendas that leverage current neurosociological methods, while pushing for new, naturalistic strategies. The latter, in particular, may be key to sociology's contributions to neuroscience, which while increasingly interested in how affect works in real situations, sociology is better positioned to bring its full tool kit to bear on this question. 


\section{Introduction}

For several decades, some sociologists have turned to evolutionary biology, neuroscience, and cognitive science to support, modify, and reconfigure existing social psychological theory (Turner 2000, 2007, Franks and Turner 2013, Turner and Machalek 2018). An upshot of this work has been to redeem a number of insights developed by Mead and many of his followers regarding the construction and maintenance of the self, taking the role of the other, and the generalized other (Franks 2019). Additionally, evidence drawn from primatology and anthropology (Maryanski and Turner 1992, Turner and Maryanski 2009, Boehm 2018), as well as comparative psychology (Tomasello 2019), further bolsters the symbolic interactionist perspective, providing evidence of the species-specificity, in relation to our genetically closest primate relatives, of human abilities for empathy, role-taking, and joint action (cf. Lents, 2016; de Waal 2019). Complementing this theoretical work, the emerging field of neurosociology has begun to specify the location and functioning of key processes and theoretical constructs in social psychological theory using neuroscientific methods (Kalkhoff et al. 2016, 2019; Niemeyer 2013). These include self-verification in identity theory (Burke and Stets 2009), expectation states in status characteristics theory (Berger et al. 1972), and solidarity in the affect theory of exchange (Lawler 2001).

In this paper, we build on this momentum by considering the relevance of recent work in affective and cognitive neuroscience for social psychological theorizing on emotions and the self. Specifically, we introduce Jaak Panksepp's (1998) theory of basic affective systems (van der Westhuizen and Solms 2015, Davis and Montag 2019, Montag and Panksepp 2019) and consider its implications for sociological theories of emotions built upon earlier work by Ekman (1982) on the primary emotions (e.g., Turner 2007). Our argument is that Panksepp's theory allows us to consider a wider range of phenomena than currently allowed in extant theorizing of emotions in social life, while extending the purview and importance of emotions to a wider range of phenomena. To that end, we show how basic affective systems may graft on, build from, and extend current social psychological usages of emotions as well as the important sociological work being done on self, from both symbolic interactionist (SI) and

identity theory (IT) perspectives. Merging Panksepp's insights with cognitive scientific 
research, we turn to the promising directions in studying emotional biographies and various aspects related to the embodiment of the self in social interaction.

\section{Why the Self?}

The notion of the self in symbolic interactionism and sociological social psychology more generally links to wider concerns in social theory via such central concepts as agency and reflexivity. Elaborating on the first (self/agency) link, Hitlin and Elder (2007:171) note that "the tools toward a more adequate understanding of the human agent are located within the vast empirical and theoretical literature on the 'self,..." Hitlin and Elder also note that a proper social psychological understanding of the self/agency link requires that the former be conceptualized as an inherently temporal phenomenon. In this respect, the incorporation of a temporal dimension into the sociological conception of the self, as done in the foundational work of Mead, "is vital for linking self and agency” (173).

The core idea behind Hitlin and Elder's effort is that we can use well-established results and conceptions on the social psychology of the self and the phenomenology of temporality to demystify the "curiously abstract" concept of agency. After this connection is made we can see that "agency's processes are less mysterious and draw on well-established scholarship on self-processes" Hitlin and Elder (2007:171).

A temporal conception of the self/agency link implies that people exert agency by imaginatively locating themselves in relation to a temporal stream in experience, looking back towards the past and forwards towards the future as they engage in pragmatic action in the present (Emirbayer and Mische 1998). This self-mediated agency, sometimes taking the form of future "projectivity" (Mische, 2009), can be located at multiple time-scales depending on the exigencies of the situation. These may range from a focus on short-term "protensions" in the here and now (at the scale of seconds or milliseconds) to larger-scale plans and projects constitutive of the life course, at the scale of years or decades (Hitlin \& Johnson, 2015; Tavory \& Eliasoph, 2013).

Re-specifying the notion of agency by linking it to the older and better-developed literature on the self in social psychology is no doubt an important theoretical advance. 
However, the danger is to trade in one very abstract concept (agency) for a relatively less abstract one (the temporally embedded self). The problem of abstraction and under-specification is only ameliorated but does not quite disappear. The reason for this is that contemporary definitions of the self in sociological social psychology are wide-ranging, and do not neatly fall together into a set of sharply specified definitions or distinctions. The concept of the self, remains (curiously) abstract.

This type of ambiguity and definitional inflation is evident in contemporary understandings of the self in social psychology. For instance, Owens and Samblanet (2013:226) define the self as "an organized and interactive system of thoughts, feelings, identities, and motives that (1) is born of self-reflexivity and language, (2) people attribute to themselves, and (3) characterizes specific human beings." Burke and Stets (2009:9) add that the self "originates in the mind of persons and is that which characterizes an individual's self-consciousness of his or her own being or identity. The self has the ability to take itself as an object, to regard and evaluate itself, to account for itself and plan accordingly and to manipulate itself as an object in order to bring about future states."

These definitions while illuminating, conflate various dimensions of the self and selfrelated processes, which hinder our capacity to make headway on key theoretical issues. At a minimum, we have mentions of a variety of self-related intentional states, such as self-related cognitions and feelings. In addition, we have a variety of self-related representations, such as identities, appraisals, or self-concepts. Finally, we have a panoply of self-related capacities or abilities such as reflexivity (capacity of the self to be an object to itself), self-direction (the capacity of the self to plan courses of action involving itself), and projectivity (the capacity of the self to locate itself in a continuous stream of temporal experience).

In the same way that Hitlin and Elder used the literature on the self to demystify the curiously abstract concept of agency, recent work in affective and cognitive neuroscience can be theoretically helpful in helping to demystify the relatively less, but still significantly abstract concept of the self in sociological social psychology. In particular, we pursue a strategy of conceptual decomposition of what are in fact distinct but causally integrated (both analytically and neurophysiologically) components of the self. This approach is particularly helpful in the case 
of the cluster of abilities that have been thought of as definitional of the self in the classical literature. Concentrating on self-related abilities is important but these are the aspects of the self that link it to agency and reflexivity, this last being the quintessential ability associated with the self (Hitlin \& Elder, 2007; Owens \& Samblanet, 2013).

Disaggregating the self into component abilities and processes is only the first step. Another way in which a neuroscientific re-specification of the self-concept can be helpful is in allowing us to see linkages and commonalities between different self-related abilities that social psychological theory conceptualizes as distinct. For instance, contemporary work on the neuroscience of social intelligence, memory, and consciousness suggests that some capacities not usually associated with temporal self-agency, such as hypothetical thinking, remembering, speculating about the mental states of others, and even spatial navigation, are actually connected to the self in theoretically illuminating, and sometimes counterintuitive ways. Thus, via a process of analytic reconfiguration, aided by novel empirical discoveries in neuroscience, we can point to novel clusters of capacities that have yet to be given serious considerations as pivotal aspects of the self in the sociological literature. This is the approach we take in what follows.

\section{Recent Work Linking Social Psychology and Neuroscience}

Recent work in neurosociology seeks to make linkages between social psychological theory and concepts and recent developments in neuroscience identifying the brain regions that partially realize important cognitive abilities and affective processes. Here we review this work, with an eye to specifying how our own contributions fits into this line of scholarship.

\section{Localizing Self-Related Abilities in the Brain}

For instance, in recent work, Niemeyer (2013) uses a decompositional strategy to show how self-related abilities emphasized in the identity theory tradition link to the underlying structural-functional brain networks that participate in their realization. According to Park and Friston (2013), the brain is organized in a network-like manner, linking nodes or (modules) via either undirected or directed links (edges) at multiple levels of organization. The nodes in the network are brain regions (either cortical or subcortical) that realize specific functions at a very 
local level. Higher brain functions are realized by linking multiple modules in a network, thus instantiating a multifunctional ensemble. When the links are anatomical (e.g., realized via dendritic connections and axonal projections) we may speak of a structural network, and when the links are based on temporal co-occurrence of activation across brain regions, we may speak of a functional brain network. Most brain networks instantiating important cognitive functions are multi-relational networks containing both structural and functional links.

Niemeyer (2013: 156), argues that the ability to engage in direct and reflected appraisals of the self is subserved by a structural-functional brain network linking "the medial prefrontal cortex, the posterior cingulate/precuneus, and multiple regions of the temporal lobe," and the capacity to tag incoming stimuli as self-relevant either explicitly or implicitly, made possible by a functional network connecting the "medial prefrontal cortex, the ventral medial prefrontal cortex, amygdala, ventral striatum, posterior cingulate cortex, and subgenual anterior cingulate cortex." A key insight of this work is that the ability to consider the self both from an ego (direct) or alter-centric (reflected) perspective share overlapping but also functionally distinct neural substrates (Niemeyer 2013: 156-157). This speaks to their status as analytically distinct but also empirically related (self-reflexive) capacities.

The same applies to the capacity to categorize environmental stimuli as self-relevant or not. According to Niemeyer (2013: 158), the key result is that activity across functionally connected brain regions seems to be highly correlated regardless of whether people are classifying stimuli as self-relevant explicitly or implicitly, thus "validating identity theory's assumption that the mind is able to consciously and subconsciously perceive self-relevant stimuli." However, while highly correlated, the brain networks in charge of explicit and implicit classification of stimuli as self-relevant are also neuro-anatomically distinct. The former relies more heavily on the dorsal medial prefrontal cortex, while the latter relies on the ventral plane of the same cortical region, indicating that while overlapping, implicit and explicit classification of self-relevant stimuli are distinct abilities.

\section{Identity Control Processes in the Brain}

Niemeyer (2013: 152-153) connects key concepts and postulates in identity theory to 
cognitive neuroscientific work on memory systems. In the identity theory tradition, identities are composed of a set of meanings attached to either role, group, social, or person identities. These meanings can be placed on a continuum from those that are socially shared and culturally patterned (and thus relatively impersonal) to those that are shaped by unique experiences specific to the person. The former is referred to as the conventional identity meanings, while the latter comes closer to the idiosyncratic pole. Niemeyer suggests that these clusters of identity-related meanings map onto the distinction between a semantic and autobiographical or episodic declarative memory system now well-established in cognitive neuroscience as developed in classic work by Squire (2004).

More specifically, while conventional or culturally patterned identity meanings map on to the semantic memory system (e.g., knowing that enacting the role identity of parent requires taking care of children), identity meanings associated with a specific parenting style map onto the subset of the episodic memory system storing generic facts about self ("I'm a strict parent"), what Niemeyer refers to as semantic autobiographical memory. ${ }^{1}$ This is distinct from the purely episodic knowledge stored as recollections of specific memories of our performance of the role as parents in a given autobiographical instance. According to Niemeyer, the conceptual validity of this mapping suggests that neuroscientific research on memory systems becomes directly relevant to social psychology in so far as it can "supplement sociological research on identity-related processes" (2013: 153). A key conclusion emerging from Niemeyer's argument is that it is possible to set up a "heuristic identity," in the sense of McCauley and Bechtel (2001) between what social psychologists called the identity standard and the total stock of semantic, semantic-autobiographical, and episodic knowledge the individual has learned and internalized with respect to a given identity (whether personal, role, or social).

\section{Measuring and Specifying Key Constructs and Processes in Social Psychology}

Beyond theoretical interventions, a burgeoning line of work linking neuroscience and social psychology has begun to make concrete empirical contributions. In particular, work by

\footnotetext{
1 In the more recent "three-dimensional" taxonomy of memory systems proposed in Rubin (2019), semantic autobiographical memory consists of stored knowledge that is high in explicitness, high in self-reference, but low in eventfulness.
} 
Will Kalkhoff, Richard Serpe, David Melamed, and collaborators has begun to use Electroencephalographic (EEG) techniques to directly measure core constructs and processes identified in social psychological theories, such as identity theory and status characteristic theory.

According to Kalkhoff and colleagues (2016), there are at least two major advantages of EEG techniques as a measurement tool over more popular alternatives such as functional magnetic resonance imaging (fMRI) or positron emission tomography (PTE). First EEG is relatively non-invasive, with reliable measures of brain activity being obtained from electrodes attached to the scalps of participants using relatively portable machinery. Second, EEG techniques capture neural dynamics at higher temporal resolutions, which is useful when analysts are not interested in making fine-grained localization determination but are instead interested in studying dynamic social processes taking place over larger time spans. Even so, gross localization determinations (at the level of neural populations and standard brain areas) can be made reliably using EEG technology.

In a pioneering study designed to explore the potential of this methodological approach, Kalkhoff and colleagues (2016) set out to address a recurrent puzzle in identity theory. The standard identity theory account (e.g., Burke and Stets 2009), argues that persons seek verification, and thus will experience negative emotions or distress whenever they receive identity relevant feedback that is inconsistent with their identity standard regardless of whether this feedback is more negative or more positive than the standard. However, laboratory research in the identity theory tradition instead finds evidence consistent with a self-enhancement mechanism, in which people do experience negative emotions when they receive more negative feedback than expected, but actually experience positive emotions when receiving identity discordant positive feedback.

Kalkhoff and colleagues make headway on the debate, by theorizing that the verification and self-enhancement processes are governed by distinct structural-functional brain networks operating at different temporal scales. First, there is the routine, unconscious monitoring of self-relevant information. This process is by a number of cortical structures constitutive of the brain's default mode network (DMN); these include, as we have seen, the 
medial prefrontal cortex (MPFC), the anterior cingulate cortex (ACC) and the precuneus. These cortical midline structures are routinely activated whenever stimuli that are connected to the self are encountered and processed. They thus serve as a possible realizer for the "comparator" function of identity theory, in which environmental feedback is routinely (and unconsciously) compared to stored identity meanings.

The phenomenon of identity non-verification, on the other hand, requires that discrepancies encountered during routine monitoring be consciously registered (so called "reflected appraisals"), suggesting that they have a distinct neuro-anatomical signature. This, Kalkhoff et al (2016) speculate, may reside in the dorso-lateral prefrontal cortex (DLPFC), a brain network that has been shown to be associated with conscious processing, deliberation, and selection between different courses of action, especially in the case of moral or risky decision-making (Greene et al. 2001).

Kalkhoff et al. thus reason that if the verification postulate is correct, we should observe DLPF activation in the face of either positive or negative identity-relevant feedback, but if the self-enhancement hypothesis is right, we should find DLPFC activation only in the face of negative feedback. Consistent with identity theory, EEG results showed that DLPFC activation was higher when study participants received non-verifying feedback (with regard to the "student" identity), however, consistent with the self-enhancement thesis, this activity was stronger when negative feedback was received, suggesting that this information was more likely to be consciously attended to and elaborated.

In a related line of work, Kalkhoff, Melamed and collaborators (2019) apply neurosociological techniques to measure what has long been thought to be a purely theoretical (and thus unobserved) construct in the research program of status characteristics and expectation states: the very idea of an expectation state. This is a core construct that has always been challenging to measure for a variety of reasons. First, the theory stipulates that expectation states are generally unconscious, and people are notoriously inefficient at reporting on implicit cognitive states (Nisbett and Wilson 1977). Second, the very fact of attempting to measure such constructs using direct approaches (e.g., questionnaires) would threaten validity as people would become aware of the research goals of the study and adjust their behavior 
accordingly.

Neurosociological measurement tools such as the EEG provide an elegant solution to this problem, as they track brain activity that is not under voluntary control using relatively unobtrusive methods. In a recent application, Kalkhoff and collaborators show that expectation estates can be measured using EEG technology in the "standard experimental situation." This involves a status manipulation in which individuals are randomly assigned to high and low status levels followed by a team task in which individuals are asked to make a choice and either stay or change their choices based on the (manipulated) choices of either high or low status partners. The idea is that people who are assigned to a low status category will be more likely to change their judgments to be in line with high status partners. "Stay" responses (when individuals do not change their initial answer) are thus indicative of higher relative status. As predicted by theory, Kalkhoff et al find that expectation states as measured by EEG recordings of brain activity associated with subjective confidence in judgments(a proxy for expectation states) partially mediates the effect of manipulated status on "stay" behavior in the experimental task: Higher status participants are less likely to experience choice uncertainty (as measured using EEG techniques) which increases the chances to stay with their original response. In this way Kalkhoff et al "crack open" the box of unobservable constructs in an influential social psychological theory, showing that what was previously thought of as an unmeasured underlying construct leaves systematic traces in neural activity that can be captured using established techniques.

Finally, some neurosociological research has been useful in measuring traces of social solidarity predicted to occur between participants who engage in consistent patterns of social exchange. In social psychology, the theory of relational cohesion, and the affect theory of social exchange developed by Lawler, Thye, Yoon and collaborators has been most concerned with linking structural conditions for exchange, affective processes, and behavioral outcomes associated with solidarity, commitment, and group cohesion.

To date, the theory has mostly relied on individual attitudinal and behavioral outcomes to measure solidarity and cohesion. In recent work, Kalkhoff and colleagues take a neurosociological approach to these issues, exploring the question of whether systematic 
exchange in an experimental condition conducive to high rewards leads individuals to experience dyadic synchronization in patterns of brain activity, indicative of social solidarity and cohesion at a neural level. In line with this hypothesis, participants who engaged in exchange in a more rewarding structural context as specified by relational cohesion theory (high total power), experienced higher levels of brain wave synchronization (as measured by their respective EEG signatures) than those exchanging in less rewarding contexts (low total power). This provides prima facie evidence that the neurosociological approach can be used to study social dynamics occurring at multiple levels of analysis, from the neural, individual, to the dyadic levels and beyond (Kalkhoff, Thye, and Pollock 2016).

\section{Charting New Paths}

As these three strands of empirically-driven neurosociology underscore, significant advances have been made in connecting both neuroscience and neuroscientific methods to theoretical elements of core social psychological theories; particularly, those rooted in the group processes experimental tradition such as Identity Theory, Status Characteristics and Expectation States Theory, and the Affect Theory of Social Exchange. To be sure, these research programs have contributed much to sociology, bringing cumulative knowledge to bear on central sociological notions and processes. In this way the emerging field of neurosociology has already both provided key support for and also adjudication on key debates (see Franks 2019 and Kalkhoff et al 2016 for recent reviews).

Nevertheless, we believe that these recent attempts at linking neuroscience and social psychology may have unnecessarily delimited the conceptual resources that neuroscience and, more broadly, cognitive science and evolutionary biology can offer to sociological social psychology broadly conceived. Thus a key goal for us in what follows is to make a prima facie case for the promise of integrating work on affect and cognition in other facets of social psychology; particularly, those facets difficult to capture by way of lab-based experimental methods (see, Turner 2006) or conventional neuroscientific measurement techniques (e.g., fMRIs, EEGs) (see Müller-Pinzler et al. 2016). Central to our concern is the way in which external social objects become essential to and emotionally significant for the self. This concern pulls ideas from broader traditions of social theory, including phenomenology, 
pragmatism, and classic symbolic interactionism, but supports them with empirically grounded research on the biological roots of various self-related and affective capacities. Our analysis also speaks to dramaturgical theory and the more naturalistic methods that might provide insight into the more speculative arguments posed by neuroscientific research on how social relationships shape and are shaped by the interaction of processes linking brain systems to the environment (Cozoline 2014).

We take as our starting point, affective neuroscience because, like social psychologists more generally, the introduction of neuroscience to sociology has relegated affect and emotion to the background, focusing on more cognitive processes. This comes as a bit of a surprise as one of the earliest and most important proponents of a neurosociology is David Franks (2006:39) who argued that:

(1) Cognitively oriented sociologists need to know about covert emotions because they so often have causal effects on the directions that overt symbolic interpretations and perceptions take...(2) Most importantly, the neuronal channels going up from the emotional centers of the brain to the more cognitive centers are denser and more robust than the cognitive centers going down to inhibit and control the emotional structures. Self-conscious efforts to avoid prejudices, fear, hatred, and depression are often rendered unsuccessful by this imbalance...(3) [Finally,] unconscious preferences and emotional leanings exert significantly more influence over our thoughts and behaviors than do conscious preferences.

When we turn to sociology, more broadly conceived, sociologists tend to define emotions as the sociocultural labels imposed on biological or bodily sensations ex post, these last are usually termed affect (see, Turner and Stets 2006; Weed and Smith-Lovin 2016). This is usually referred to by analysts as a constructionist approach to emotions, which can come in either "sociological" or "psychological" flavors. Feelings and sentiments refer to the expressive side of emotions, while moods are longer lasting affective states that motivate or constrain action and which have definite temporal limits (Frijda 1996).

Despite the constructivism usually assumed about emotions, the vast majority of sociological theorizing on the subject begins with conventional classification systems identifying four or five basic or primary emotions (Tracy and Randles 2011), such as the classic Ekman (1982) typology). A massive body of experimental and cross-cultural work provides evidence consistent with the idea that primary emotions are universal in the human species, and thus possibly innate (Turner 2010). Given this, interest in the role of emotions in social 
life splits along three paths, which we refer to as the dimensional, dramaturgical, and structural approaches.

First, there are those sociologists interested in higher level properties of emotions falling into some typological or dimensional space (e.g., negative or positive; powerful or powerless; active or quiescent), in the group processes tradition (e.g., Burke 1991; Lawler 2001). Here, emotions do not enter the picture as distinct, disaggregated behavioral and affective gestalts (e.g., anger, fear, sadness, happiness, etc.). Instead, abstracted properties of emotions (usually valence or potency) are seen as signals of congruence or incongruence between identity meanings and reflected appraisals (Burke and Stets 2009), fit between expected fundamental sentiments and perceived or experienced events (Heise 1977), or consequences of successful joint task outcomes and, subsequently, causes for increasingly nonutilitarian attachments (Stryker and Serpe 1982, Lawler et al. 2009).

The second way sociologists theorize emotions shifts the focus to the so-called social or self-conscious emotions, or those that appear unique to humans and which appear to have had important evolutionary advantages (Turner and Maryanski, 2009; Boehm, 2018). These include shame, pride, embarrassment, and the like. The most influential line of work in this tradition, associated with the "dramaturgical" school (Goffman 1967), follows Cooley's insights on the looking-glass self, exploring how the self-conscious emotions, and in particular shame and embarrassment, act as powerful drivers of self-regulation, mutual face-saving, conformity to local rules, and social control (Scheff 1988). Work on the "management" of emotion in formal and informal settings also fits into this tradition, looking at how people in subordinate roles are induced to control and regulate their own emotional expression and feelings, but also manage the emotions of superordinate others (Hochschild 1983).

The final common track builds on the dimensional and dramaturgical approaches, but adds a more concerted social structural and relational lens. This work focuses on the uneven distribution of emotional experience across for people located in different structural positions in social space as defined by the status and power dimensions. Like dimensional theorists, structural emotion focus on broad abstracted features of emotional experience (e.g., negative and powerful emotions such as anger). Like dramaturgical theorists, however, the structural 
approach emphasizes the relational settings giving rise to particular types of emotional experience. Thus, these theorists theorize how power and status shapes an individual's cultural expectation (and probability) to express or suppress a given emotion. They also look at how specific affective processes (e.g., superiors directing anger at fearful inferiors, or experiencing

pride when receiving a compliment from a status-equal) become central features of relational ties nested in hierarchical social units (Kemper 2006, Ridgeway 2006).

Excepting some lines of dramaturgical researchers that see actors as actively dealing with the ever-present specter of affect and emotion, most social psychologists fit emotions into their models in a way that makes them a dependent (or intervening) rather than an independent variable. This approach ignores Franks' (2006) warnings that emotions are often causally primary in relationship to cognition and Damasio's (1994) groundbreaking work demonstrating the inseparability of emotion and decision-making; as well as the fact that the brain's neuro-architecture evinces deeper neuronal channels going from the affective to the cognitive centers than vice versa. Add to this the fact that emotion centers are not simply hardwired, but change over the course of an individual's life due to learning (Asma and Gabriel 2019).

Emotions, then, are essential to most social psychological theory in sociology (Weed \& Smith-Lovin 2016), yet, social psychologists have generally been slower to leverage insights drawn from broader evolutionary, biological perspective on emotions (cf. Turner, 2010). Some of this literature has been introduced to sociology (for a sweeping review, see Franks 2019)— such as the neural foundations of role-taking in mirror neurons (Iacoboni 2009), but has not diffused too far. Below, then, we introduce some affective neuroscience that may help bridge those sociologists oriented towards neuro and cognitive science with a broader swath of sociologists. In particular, we point towards two key points of innovative integration: (1) emotion biographies, where strong points of supplementary overlap reveal themselves and (2) embodiment, where we are best able to fuse affect and cognitive insights together.

\section{Emotions in Human Social Evolution}

Turner $(2000,2010)$, whose work, like Durkheim's, places emotions at the center of his 
theory of human evolution, has long argued that understanding the neuroscience of emotions is essential to understanding human social behavior and organization. There are a number of observations taken from work on primate evolution essential to his argument. First, apes are visually dominant, contributing to the exceptionally accurate facial recognition abilities gorillas and chimps wield when determining whether a conspecific belongs to the community or is, indeed, a stranger (de Waal, 2019). Visual dominance, however, also improved the ability to attune to emotions of others as well (Lents, 2016). Furthermore, the more upright apes became, however, the more their bodies were exposed and the more information they had to read, hence the growing body of research that suggests that many emotions are ubiquitous in bodily language as much as facial gestures (for a review, see Witkower and Tracy 2018). These are all insights echoed by both the dramaturgical school, socio-linguistics and conversation analysis (Collins, 2004; Goffman, 1981; Sacks et al., 1978). That is, because humans command these inherited abilities, like chimps, they also pay extraordinarily close attention to non-verbal signs of emotions. This enhances the role emotional experience and expression play in a whole host of social psychological processes (Hochschild, 1983; Kemper, 2006; Shott, 1979). Indeed, it is also possible these preadaptive ape characteristics set the stage for the foundations of morality that underscore the rise of the social self.

Second, as early hominins lost their animal defenses (sharp claws, powerful jaws, speed, strength), two evolutionary cross pressures took effect: one was for some mechanisms facilitating cooperation, as group cohesion would be paramount to survival (Bowles and Gintis 2011; Boehm 2018), and the other was a need for control over emotional outbursts that would jeopardize group hunts, which had become increasingly essential to hominin survival (Turner, 2007). Given the vulnerabilities of our ancestors and the neural raw material available for evolution to work on, the human neocortex was rewired "to produce an animal that could use and read a wide variety of emotional cues for enhanced social bonding” (Turner, 2000:21). This meant hominids who could "quiet" their emotions were advantaged over those lacking control, jump starting an evolutionary process resulting in the growth in the size and complexity of the human brain's emotion network. Consequently, this rewiring led the expansion in depth and sophistication of communication between conspecifics (indeed, most 
neuroscientists and paleontologists believe expression of emotion preceded verbal language [Asma and Gabriel, 2018; Cochrane, 2018]) and, would contribute to the necessary rewiring of the brain for real language (Damasio and Geschwind 1984).

The wrinkle in Turner's argument centers on a Durkheimian insight that connects to one of the dominant threads in social psychology: if affect was central to the construction of human sociality and continues to undergird social relationships, then we must reckon with the basic fact that there was not a lot to work with because every list of primary emotions identifies one positive emotion (happiness and its variants in intensity) and at least three negative ones (sadness, fear, and anger). Thus, if bonds linking individuals to each other, to groups, and to the types of external groups of personal and sometimes impersonal others like tribes or nationstates involved emotions (Lawler et al 2009), then how did evolution work with a single positive emotion?

The answer is that the evolution selected for a more complex human affective neuroarchitecture with an enhanced ability to mix primary emotions like paint from a palette on a canvas. For instance, awe is a combination of fear as the primary emotion and happiness as the secondary emotion: standing in front of something that is bigger, more powerful produces both terror and joy. The social and self-conscious emotions, then, can also emerge from this combinational process. In this sense, they are what Turner (2010) calls tertiary: shame, for example, is sadness for the self, anger towards the self, and fear for the consequences of the self.

While Turner's evolutionary model is both suggestive and potentially generative, it is a start and not the last word on the subject. To be sure, Turner's point about the paucity of positive emotions is suggestive, and we will return to it below. The same goes for the primacy of body language, which points to some limitations in experimental social psychological research. However, our first task is to extend and elaborate on Turner's combinatorial model of emotions and emotional experience. To do so, we turn to a body work on affective neuroscience. 


\section{Affective Systems}

A fruitful place to begin is with the work of Jaak Panksepp, who has brought evidence to bear that there are seven distinct affective systems in the brain. Rather than provide the usual typological list of emotions, Panksepp (1998) takes an evolutionary approach, arguing that basic problems put pressure on animal brains leading to the rewiring of the brain (for a review, see Davis \& Montag 2019). As primates branched off of mammals, and then apes off of primates, and humans off of apes, these basic problems remained the same, in many ways, but changed in the specific environmental pressures. To be sure, Panksepp's systems are not incompatible with the usual Ekman-style list of primary emotions, but push us to think about the brain's architecture more seriously and the role emotions play in the type of motivational states that affect social behavior and, therefore, social structure which emerges out of recurring feelings, thoughts, and actions only to pattern future feelings, thoughts, and actions. This point, of course, is supported by data found elsewhere and, as others have argued, the brains affective architecture delimits what is possible in social organization. The systems approach, then, matters to thinking about what aspects of human behavior may be central to social psychological research.

The brain's emotional system involves three layers ordered by the sequence in which they evolved (MacLean 1977). The reptilian and oldest layer; the limbic layer; and the neocortical layer. It is tempting, especially in sociology, to emphasize the latter's impact on emotions in humans, where art, religion, humor, and other ramified social endeavors express some of the greatest human achievements. And, it is undoubtedly true that human's cognitive functions transform the 'raw' biological experiences of environments and existence into symbolic representations (Panskepp 2005). However, to the best of our knowledge the power of emotionality arises from subcortical systems that also sway the minds of non-human animals (Turner, 2000). Hence, Panksepp identifies seven basic systems within the first two layers of the brain that shape human intentionality as an organism and, especially in childhood, are shaped by the sociocultural environment (Asma \& Gabriel, 2019; Davis \& Montag, 2019).

These are the SEEKING/Expectancy, RAGE/Anger, FEAR/Anxiety, LUST, CARE/Nurturing, GRIEF/Sadness, and PLAY/Social Joy systems. Here we follow 
Panksepp's convention and use of capitalization to distinguish the primary emotional brain systems from the folk labels for the typical emotions associated with each system (in lowercase).

Unlike a lot of evolutionary psychology premised on finding modules of some sort in the future, Panksepp's systems have discrete etiological roots in brain areas and neurochemistry (van der Westhuizen and Solms 2015:20). Subsequently, these systems are biologically predisposed to respond unconditionally to proprietary stimuli, and often control motor programs as well as, potentially, behavioral sequences aroused by stimuli (Panksepp, 1998:48-49). They reciprocally interact with other brain networks responsible for higher decision-making and consciousness; accordingly, they also become intimately involved in attitudes and behaviors learned during the course of child and adult development. To be sure, even after acquiring culture and social rules, emotion systems continue to rest at the "core of value generation" and are responsible for accelerating/decelerating and giving meaning to motivating action and in our "response toward associative or true reasoning processes" (Asma \& Gabriel 2018:32). These basic systems either reside in or traverse one or more of the layers of our brain.

For instance, the oldest layer evolved to deal with the most enduring environmental challenges and their realization (Panksepp 1998:50). These include (1) the search for survival resources (or the SEEKING/expectancy system); (2) the urge to protect them (RAGE/anger); (3) the urge to avoid pain and destruction (FEAR/anxiety); and (4) the urge to identify and pursue potential mates (LUST). However, a secondary-level was eventually built upon this, emphasizing the sociality of primates, but growing bigger and more prominent in apes and, especially, hominins. This layer is responsible for (5) the pangs of rejection, separation, or isolation from significant others (GRIEF/sadness), (6) the need to care for offspring (CARE/nurturance), and (7) the desire to engage in vigorous social interaction that is responsible for social bonding (PLAY/social joy). Each of these systems may be activated in executive functions (when the system exerts superordinate control over a set of cascading processes), in command functions (the system takes over total control over everything else), and, finally, in operative functions (contributing to the coordination of other functions). 
The tertiary layer, most familiar to readers in that it is the domain of philosophers and social scientists-e.g., language, symbols, writing, planning, and so forth-is not a site of affect, but is essential to the way emotions and thoughts interact to produce the self (Damasio 1994, LeDoux 2000, Conway 2005). In short, the primary level shapes the secondary level by facilitating and constraining learning and development, while the secondary gives shape to the tertiary via rumination, mental time-travel, and unconstrained thinking (to be discussed below). Conversely, the tertiary layer affects the secondary one via cognitive regulation - as we acquire rules, norms, symbols, and so forth - such that the secondary layer, in turn, can facilitate or constrain the conditioned responses acquired by the primary one. Thus, while the third layer makes us recognizably human it is, in fact, the secondary layer where the social affective systems of GRIEF, CARE, and PLAY originate, and where "primary-level processes interact with associations or mnemonic schemas" (Asma \& Gabriel, 2018:33).

\section{Affect and Social Action}

Panksepp's underlying assumptions are compatible with Turner's insights and with pragmatism, suggesting a potential generative synthesis. On the one hand, affective systems are hardwired to attune humans to certain features of their environment and to marshal resources to realizing them. The theory of action implied by affective neuroscience is compatible with pragmatism: Persons act habitually and automatically unless a "problem situation" is encountered, producing the experience of frustration, obstacles, or unanticipated affect in the routine pursuit of these basic goals (Gross 2009). Because of the secondary layer's linkage between cortical and subcortical brain structures, higher level cognitive functions come into play, sometimes taking over the control of action, and other times acting in tandem with subcortical affective systems. Cortical systems are intimately tied to our ability to learn and adapt as an organism, which means they are plastic and responsive to experience. The environment, as is assumed in symbolic interactionist theory, can shape them, deepening some systems' relevance and atrophying others'. Humans are, then, instinctively SEEKING or CARING, but the objects that activate one or the other and, therefore, the behavioral directives that result, are vary in culturally and situationally-specific ways. More importantly, a panoply of tangible and intangible goals that "fit" into one or more systems. 
For instance, middle class Americans do not have to search long and hard for food, water, or shelter as these are often taken for granted features of affluent, modern society, for those who are privileged. Yet, the SEEKING system regulates the formation and engaged pursuit of goals more generally beyond basic needs. Thus, infants learn the types of goals worth pursuing both from their parents' intentional efforts and from the ecological space they develop within. And, as Lareau's (2011) work, among many others, suggests SEEKING is shaped by distinct class cultures. Yet, the desire to SEEK is part of human nature (Smith, 2015), and given the right environmental conditions (e.g., abject poverty), can be central to or even take total command over the organism's or the collective's (the family's) entire decisionmaking.

In addition to the goal-oriented nature of affective neuroarchitecture, these systems, and their effect on goal-oriented pursuit, are activated by relational and environmental objects, which are given significance and meaning by way of social learning (Williams et al., 2009). Thus, we feel happy or sad in relation to an object and the meaning assigned to the object. This may not come as much of a surprise for social psychologists, as the role of emotions in shaping micro-level goals like verification, trust and uncertainty, reciprocity and fairness, and so forth has featured prominently in myriad work since at least the 1990s (Robinson et al., 2006). However, most scholarship has tended to either focus, vaguely, on "global" properties of emotional experience, like valence or potency, as cues for behavior (Lawler et al., 2009; Robinson et al., 2006), or conceptualized emotions as rule-like resources to be used (Hochschild, 1983). In this respect, the emphasis has tended to be on the operation of a single affective system or another in research.

For example, Scheff's (1988) shame-deference system leverages the GRIEF system, pointing to a central drive of humans: to avoid rejection. This system, incidentally, also seems to shape most "control" models in sociology such as identity or affect control theory (Burke \& Stets, 2009; Robinson et al., 2006), while taking for granted how we come to even learn the meanings of identities or statuses that we feel compelled to commit. Status expectations and status belief theories have emphasized, though less explicitly, how status characteristics and micro-orders activate RAGE and FEAR, as superordinates desire to protect their status and 
subordinates fear either suffering the consequences of failure or losing the social tie that provides what little status they possess (Kemper, 2006; Ridgeway, 2006).

The affective neuroscience approach, conversely, emphasizes a more synthetic view of emotions and their impact on self and its many components, pointing in many potentially fruitful paths. This can help to deal with a number of puzzles that have cropped up in conventional approaches to the sociology of emotions. For one, there are three or four negative primary emotions (sad, anger, fear, and, perhaps, disgust) and only one positive (happiness), which means either the probabilities for bonding is low or, as Turner (2007) has suggested, negative emotions require "blending" with happiness to produce solidarity. Put differently, while positive or negative appraisals or attributions make sense in experimental or survey research, they mask the variation in emotions generating relational cohesion in myriad settings. The negative valence of piacular effervescence can produce solidarity (Durkheim 1912 [1995]), in the same way that high levels of integration in abusive domestic relationships can be driven by the RAGE or FEAR systems (Summers-Effler, 2004; Sweet 2019), even when the relationships result in harm and pathology for one or both of the partners involved (Barber et al 2018).

What Panksepp's model suggests, then, is that we should move beyond a sole focus on global properties of emotions or trying to link these abstracted properties (e.g., valence) to specific outcomes (e.g., conflict, solidarity). Instead, the affective neuroscience approach encourages us to think about how relationships can be based on the simultaneous activation of multiple affective systems and associated emotions. These include GRIEF, CARE, or PLAY as well as on FEAR of losing valued resources (like a sexual partner) or RAGE in seeing threats to one's resources. The other insight, as relayed in the work of Franks' (2006) above, is that the operation of these emotion systems may be a precursor to higher level cognitive and behavioral outcomes. In this way, affective systems can have stronger direct effects on social relationships than cognitive appraisals.

Additionally, these systems may interact in normal and abnormal ways, leading novel empirical predictions and theory-building insights. For example, sociological research on the self-conscious emotions has tended to emphasize shame (Scheff, 1988), and to a lesser extent 
embarrassment (Goffman, 1967; Lizardo \& Collett, 2013), as central—in the negative senseto bonding with much less thought given to the positive emotions of pride, honor, and dignity (see, for some recent research on the evolutionary adaptivity of pride, Tracy (2016)) or the positive, motivational qualities of shame (Abrutyn 2019) - e.g., GRIEF and PLAY can be combined to imagine actors working to avoid rejection by following the rules learned through appropriate social interaction. Building on these points, the following section examines some points from which these insights merge with extant neurosociology, cognitive science, and social psychology in potentially fruitful ways.

\section{Affective Systems and the Narrative, Projective, and Embodied Self}

The Biographical Ape

A running thread in sociology of emotion scholarship emphasizes the actor's development of an emotion biography (Denzin 1985, Clark 1987, Johnson 1992, Kemper 2006). The logic of the argument is that reflexive self-understanding, constructing the self as a historical object from past events "chosen" as relevant to a consistent, coherent, temporallyordered life-narrative, is shaped by affect as much as by cognition (Collins 2004, SummersEffler 2004). This is a finding that is, incidentally, supported by the role affect plays in memory consolidation processes (Whitehouse 2004).

Sociological work on this topic begins with the typical argument focused on "valence," noting that biography can be built on positive or negative affect, usually of the intense variety. The affective neuroscience approach can help us broaden this focus. First, the biographical self can be forged from interaction ritual chains activating one or more of the specific emotion systems. Persons experiencing extreme poverty and material deprivation may develop an overriding emotional self-signature and cognitive style via experiential links to the SEEKING system (Mullainathan \& Shafir, 2013), whereas sexually or physically abused spouses or children may mix FEAR, RAGE, and GRIEF together to form an intensely shamed self (Summers-Effler, 2004; Sweet 2019). Likewise, marginalized groups in war-torn nations socialize children through FEAR and SEEKING. Following pragmatism and theories of habitus, people can become routinely adept at some affective, cognitive, and behavioral suites 
and not others because of the uneven distribution of experiences and resources. The cognitive roots of human biographies, then, may be saturated in one or more systems that either exert superordinate control, total command, or contribute to higher-level cognitive functions.

To be sure, the human ability to monitor and encode autobiographical information and its implications have been elaborated in recent work (Niemeyer, 2013; Franks, 2019). This line of research supports the idea that a number of self-related abilities, inclusive of personal memory and the ability to imagine possible futures (Hitlin and Elder, 2007), share a common neural substrate within the so-called "default mode network" (DMN) (Raichle, 2015). The $\mathrm{DMN}$ is a set of structurally and functionally connected brain regions (really a brain network composed of linked subnetworks) that become active when people are not attending to external stimuli and instead switch attention to the Jamesian "stream of consciousness" constitutive of the internal world of subjective experience and imagery, or what "Schutz...called duration: a 'continuous coming-to-be and passing-away' of undirected thoughts, which is phenomenologically experienced as the constant transition from a 'nowthus' to a 'new now-thus"' (Niemeyer 2013: 160).

These brain areas include the medial-temporal lobe, medial parietal region, and the temporoparietal junction, sites mainly involved in planning (prospection) and autobiographical memory (retrospection) (Buckner \& Carroll, 2007). In addition the DMN comprises the lateral prefrontal cortex (involved in working memory processes), the occipital cortex (involved in visual mental imagery), the posterior cingulate cortex and precuneus, medial prefrontal cortex, and lateral temporal regions, the last two involved in imaginative or reconstructive processes specifying the self as the main actor (Spreng et al., 2009). As such, the DMN is implicated in seemingly all activities involving the imagining of hypothetical or previously experienced scenes in which the self is involved in some capacity (Niemeyer 2013:160-161).

These empirical findings have led some analysts to propose that it is more appropriate to speak of a generalized capacity for "mental time travel” (MTM) (Michaelian, 2016), rather than strictly segregated "remembering" and "future projecting" abilities. According to the MTM hypothesis, the self can be either projected into the past to (re)construct past events (autobiographical memory) or into the future (projectivity) to construct possible or 
hypothetical events. The former capacity is crucial relating past experiences to present contingencies so that past learning can inform current choices. The latter capacity is crucial for the human ability to construct plans and action projects based on hypothetically imagined futures (Frye, 2012). Both types of "self-projection" require autonoetic awareness or the sense that the constructed or reconstructed imaginings (whether located in the future or the past) involve the self (Schacter, Addis, \& Buckner, 2007).

\section{The Projective Ape}

Buckner and Carroll (2007) have proposed that what all of these things have in common is the fact that in all cases, the self is "projected" onto a constructed or imagined mental space, and thus uncoupled from the immediate present. This could be the (re)constructed past, the imagined future, a hypothetical counterfactual or daydream space, or the space of reasons, motives, and desires of a conspecific. As the Social Psychologists Adam Waytz and Jason Mitchell put it:

[T] he same neural regions that subserve the human capacity to contemplate oneself experiencing events outside of the here-and-now also subserve the capacity to imagine the mental states of other people. This overlap suggests that the cognitive mechanisms underlying people's ability to mentally conjure up fictitious experiences are also those that allow people to mentalize about the internal states of others, consistent with the notion that perceivers engage in similar types of self-projection regardless of whether the counterfactual experience they are considering involves thoughts about a hypothetical time and place or the possible goings-on of another mind (2011:198).

This self-projection (SP) hypothesis, thus brings together, via analytical reconfiguration, a variety of self-related abilities that have been treated as distinct in standard accounts and definitions of the self in social psychology, while pointing to their shared phenomenological, cognitive, and neurophysiological realizers. This also means that it is possible to see this SP capacity across all dimensions of human experience (not just the temporal) as crucial for linking self to agency. This is in contrast to recent work on the self-agency link emphasizing temporal projectivity at the expense of the other projective abilities (Hitlin \& Elder, 2007; Mische, 2009; Tavory \& Eliasoph, 2013).

These insights, focusing on purely cognitive self-related abilities can be integrated with insights from affective neuroscience. A number of considerations emerge from this synthetic 
perspective. First, affect can drive cognition independently (Damasio, 1994; Cozoline, 2014) and therefore the hardwired affective systems delimit the type of autobiographical information one may encode and use for self-related narratives. Second, (2) biographies, and therefore, an emotional signature or tone, can extend beyond the individual's own autobiography because the DMN and self-projectivity allows for the sort of interpersonal self-projectivity into the space of other minds (and their beliefs, feelings and concerns) required for empathy (RuizJunco 2017), social inference and role-playing (Tomasello, 2019), as well as the purely "imaginative" projectivity into hypothetical worlds required for participation in certain social institutions and "make believe" worlds (of the sort considered by Schutz (1967)). These projective capacities not only help create and solidify affective bonds, but in Durkheimian terms, reify relationships, groups, and classes of people with agency and, therefore, affective biographies of their own (see, Kemper, 2006). That is, humans have the unique ability to blur the boundaries between ego and alter(s) (Aron and McLaughlin-Volpe 2001) and attribute positive or negative affect to abstract others (Lawler, 2001). In this respect, people are impacted as much by a relationship's or group's emotional biography as the experience of their own. Indeed, that the human self is anchored in identities that are only meaningful within the context of generalized role-relationships, group membership, status categories, and significant others indicates just how collective our autobiography actually is (Turner, 2010).

Hence, what is true of autobiography, is true of collective biographies. Marriages and friendships may be sustained via the operation of one or more affective systems; and, consequently, these systems may exert higher-order control, total command, or reciprocal effect on cognitive functions related to interaction and communication. Likewise, a highly segregated ethnic community that is subjected to intense surveillance and physical repression by the state, is not just a community locked in an anger-shame feedback loop waiting to explode (Scheff, 1988). It is also a community filled with individual's whose RAGE emotion systems are chronically activated at the expense of many others. The members, in turn, will overwhelmingly perceive problems related to RAGE and resources as more salient than other problems that other actors will perceive.

This is consistent with the symbolic interactionist idea that humans acquire meanings 
via interaction that they use to interpret the past and present and anticipate the future. Meanings, however, are not simply linguistic content, but like all information, are subjected to affective tagging the shapes their importance (Wentworth and Ryan 1992, Wentworth and Yardley 1994). The input is "assigned" an emotional valence, with stronger valences leading to more fine-grained perception, and a significantly higher likelihood of being remembered, while the emotion system primacies some behavioral responses over others. We are more likely to recall, faster and readily, intense emotionally tagged memories than those deemed less relevant (Turner, 2007); hence, the enduring effects of trauma.

If the self is, in essence, a series of experiences encoded in neural pathways generating a consistent, coherent biography (Thagard 2014), then it is plausible to suggest that if one system is disproportionately activated by a given environmental stimulus, it becomes increasingly subsequently even more sensitive to that type of stimulus via a habituation process. We know, for instance, that areas of the motor cortex controlling the right hand of a violinist grows in size and connectivity as they practice from a young age (Schwenkreis et al., 2007). Hence, a community can come to experience the world through a specific affective lens, leading to distinctive patterns of social behavior that would be hard to make sense of without understanding the interaction between neuroarchitecture and the social environment. Occupying subordinate or superordinate roles across interaction rituals can also come to shape brain networks in charge of emotionally coping with position in status systems in much the same way. Worse, being subjected to repeated rejection and isolation may lead to overactivity in brain networks associated with GRIEF and RAGE. Consequently, the self comes to be defined in affective terms that both shape future interactions (as depressed or manic) and selfattributions. Thus, the self is built not only via the acquisition of language and related cognitive abilities, but also of distinct affective and emotional signatures modulated by social experience.

Integrating affective neuroscience and symbolic interactionist insights in thinking about personal biography opens up new methodological and empirical questions. From the vantage point of neurosociology, using neuroscientific methods (e.g., EEGs) to understand how different affective systems influencing selfing and minding across different types of identities becomes possible, as the subcortical networks typical of each affective system have 
been identified (van der Westhuizen and Solms 2015). Sociologists, especially social psychologically trained sociologists, are surely well-positioned to develop creative ways of examining just how much relationships and broader culture and structure are shaped by and shape the affective systems and our identities—something neuroscientists are interested in but struggling with (Müller-Pinzler et al., 2016). But, it also pushes us to consider more traditional methods, either naturalistic observation or experimental, and creatively develop instruments for comparing different relationship biographies and their outcomes, as one example.

The biographical nature of self is, as Mead (1934) contended and neuroscience seems to support (Franks, 2019), truly rooted in the ability for self-objectification. However, what neurosociologists and social psychologists alike have taken for granted, is just how central embodiment is to communicating affect and cognition. Therefore, if embodiment is predicated on our ability to objectify things, which includes the social self, then it too is premised on the capacity for "affective tagging"; that is, the object must activate one or more emotion systems either as something good (SEEKING, LUST, CARE, PLAY) or to be avoided (RAGE, FEAR, GRIEF), and our dispositions and style of bodily communication may also be saturated in one or more of these emotion centers. The human self, considered as an object, may be built on one or more of these during development, and thereby, so may identities attached to real others, a real collective other, status characteristics shared with culturally-specific classes of others "like me," or even a vague, abstract collective like a sports team or a society (Durkheim \& Mauss, 1963). As such, affective dynamics come to play a central role in the selfing process via the filtering and selection of significant and nonsignificant information about the environment.

\section{The Embodied Ape}

The discovery that the DMN provides a common neural substrate for a variety of selfrelated abilities theorized in the social psychological literature provides an important avenue to link sociological social psychology and contemporary cognitive neuroscience, and also Panksepp's (2005) ideas. However, note that the self-related abilities discussed so far involve generally "offline" aspects of self-related agency, primarily in the form of temporal or interpersonal imaginative self-projection removed from action. This corresponds to the largely 
intellectualist and somewhat disembodied conceptions of the self that dominate contemporary social psychology. As noted earlier, for instance, current definitions of the self emphasize highlevel cognitive processes (such as self-reflexivity) or emphasize self-related representations and cognitions (as well as self-directed affective meanings).

However, the self is more than a bundle of self-related cognitions or imaginative simulations. As noted in the tradition of embodied phenomenology that begins with MearlauPonty (1962) a key aspect of the self is grounded in concrete (perceptual) self-representations of our bodies and appearance. This includes the most pivotal aspect of the embodied self consisting of our capacity to recognize our face (and body) in the mirror, a capacity humans share with other species of non-human animals, including the great apes, dolphins, elephants, and even magpies (among a growing list). In this respect, contemporary accounts of the self in social psychology can stand to benefit from greater integration with strands of social theory emphasizing the direct embodiment of social cognition (Barsalou et al., 2003). Furthermore, both of these literatures could benefit from considering the role affect plays in embodiment; particularly, how we come to signify our moral self by transforming our corporeal existence into a social object via performance.

The issue then becomes whether we should analytically disaggregate the bundle of capacities associated with (relatively disembodied) self-projection from those associated with more concretely embodied capacities for perceptual self-recognition. In addition, another question that opens up is whether there are embodied analogues for the interpersonal selfprojection capacities; just like people can put themselves in another's person's "mental space" using explicit representational vehicles, can they use embodied-self resources to empathize with others at the level of action and direct experience? Contemporary work in the cognitive neuroscience of embodied self-representation provides a positive answer to both of these conjectures (Uddin et al, 2007; Van Overwalle \& Baetens, 2009; Waytz \& Mitchell, 2011).

\section{Self-Recognition and Embodied Understanding}

In terms of the first issue, recent work reveals the existence of dedicated right frontoparietal networks that selectively activate at the sight of a person's own face (but not other 
faces). Some studies also show selective activation of the same region to hearing the self-voice, suggesting that this area encodes a multimodal embodied representation of the self. Importantly, the embodied self-recognition network shows strong overlap with the related mirror neuron system (MNS) in the human inferior frontal cortex (Uddin et al, 2007).

The MNS is distinctive in being activated by both self-generated actions and by perceiving similar actions, in terms of effectors (e.g., hands versus feet) used, specific motor trajectories, instruments, objects, and goals, performed by others (Gallese \& Goldman, 1998). As such, some have proposed that the MNS is most likely candidate area capable of supporting a type of embodied intersubjectivity allowing for the attunement between self and other at the level of action and practice rather than explicit representations such as beliefs, desires and the like (Lizardo, 2007, 2009). In this last respect, this sort of self-other attunement, and action "understanding," is analytically distinct from the mentalizing version of self-projection, which relies on the imputation of a variety of explicit cognitive and propositional states to others in a simulated mental space (Kalkhoff, Dippong, and Gregory, 2011).

Additionally, the overlap between the fronto-parietal embodied self-recognition network and the MNS network points to the possible existence of an embodied "I/Me" dialectic happening purely at the level of the body and practice sans the mediation of explicit representations. The idea here, is that when we perceive ourselves in a mirror or see ourselves performing an action, the same mirror system used to attune ourselves to others at the motor level is activated. This allows for a form of practical self-attunement, or embodied selfreflexivity at the level of action, in which "the perceived self is mapped onto the perceiving subject's motor repertoire" (Uddin et al, 2007, p. 154). This provides a systematic link between the perceptual "body-image" and the toolkit of embodied skills and abilities generative of action, or "body-schema" (Gallagher, 2005).

Self-recognition thus goes beyond the passive processing of perceptual self-related information to include a type of pragmatic self-relation in which perceived self-generated actions "resonate," via the mirroring process, at an even higher level of intensity than the perception of the same actions performed by others. Importantly, this account preserves insights from the symbolic interactionist tradition on the origins of the self (Mead, 1922), in 
which we first establish a link between self and other (via the mirror mechanism) before being capable of a reflexive self-relation. The latter emerges in ontogenetic time when self-other attunement capacities (supported by the MNS) are co-opted and linked to established perceptual self-representation networks.

\section{The Projected Self versus the Embodied Self}

Overall, the preceding suggests that two modes of self-other linkage, empathy, and "understanding" correspond to two modes of self-reflexivity (Van Overwalle \& Baetens, 2009; Waytz \& Mitchell, 2011). This is a case in which cognitive neuroscience allows not only for

analytic decomposition, but for the proposal of empirical partition into separate abilities, of self-related capacities, such as "reflexivity" and "empathy," that have been treated in unitary terms in social psychology, by focusing mainly on the less embodied kind (Niemeyer, 2013).

In the first "offline" mode, we can relate to both self and others by decoupling from present concerns and engaging instead in simulated activity in which the self is projected into hypothetical, counterfactual, future, past, or interpersonal imagined spaces (Schutz, 1967). This involves the use of mentalizing ('theory of mind") abilities to put the self in the space of other people's explicit beliefs, concerns, desires, intentions, and considerations, thus being able to see the world through their eyes and attempt to make sense of, or even predict, their actions. This type of "projective" empathy is at the root of the more cognitively mediated types of self-other understanding emphasized in the Germanic (and more specifically Weberian and Schutzian) tradition in social theory under the notion of verstehen. This projective approach seems to also be the dominant conceptualization of the notion of empathy in social psychology that emerges from Cooley's pioneering work (Ruiz-Junco, 2017). As we have already seen, this abilities are partially realized in the brain's Default Mode Network (DMN).

In the second, "online" mode, we relate to self and others in the here-and-now, making sense of their perceived, situated activity by matching our embodied capacities to the perceived action pattern of conspecifics (Lizardo, 2009). Rather than being "projected" into a hypothetical, counterfactual or non-present temporal space, the (embodied) self relates to perceived others directly in the situation at a practical-emotive level, by attuning the body- 
image and the implicit body-schema to the perceived goal-directed or expressive activity of others. This process couples the observation of other people's actions, facial and emotional expressions and the like with our own embodied capacities to produce the same actions and postures. This type of "mirroring" empathy is at the root of our capacity to "feel" other people's pain or suffering, or partake in their joy and happiness, when directly exposed to others undergoing painful or happy experiences (rather than imagining such experiences offline in the absence of others). This is also what allows for non-deliberate processes of emotional contagion and attunement.

The capacity for direct self-other resonance may also be critical in processes of active pedagogy in which people pick-up fine-grained practical abilities from others by establishing correspondences between perceived skillful performances and their own, "beginner" actions (Lizardo, 2009). There's no established tradition in social theory emphasizing this type of perceptual, embodied attunement to others for analytic purposes. Nor is there much work that specifically works to tease out how observation and disclosure work in tandem or independently in developing self or behavioral repertoires. Iacoboni (2009), for instance, has shown that when two groups of deaf children, previously separated from each other, were brought together an entirely new local non-verbal grammar emerged. Younger children, in particular, when exposed to older children and this "indigenous" language developed an extensive sign language.

In this way, mirror neurons allow for the non-propositional "understanding" of others' actions and emotions via observation, thus facilitating imitation and the transmission of practices from an expert to a novice (Lizardo, 2009; Summers-Effler, et al 2015). This is even though humans can also transmit practical abilities via linguistic communication. Yet, how and why these embodied versus linguistic pathways are different and similar remains unexplored. To be sure, both recent and classic work on the roots of empathy in the sociology of emotions does emphasize forms of non-cognitive and more directly emotive forms of self-other attunement (Ruiz-Junco, 2017; Shott, 1979).

More generally, recent work in practice theory and ethnographic methods under the guise of "carnal ethnography" (Wacquant, 2015), and an intellectual movement in 
anthropology under the banner of "neuro-anthropology" (Lende and Downey, 2012), has begun to make a case for the importance of forms of direct self-other attunement by-passing linguistic mediation. The potential for this sort of connection between social psychology and neuroscience are most clearly delineated by Summers-Effler et al., (2015). According to these authors, the discovery of mirror neurons linked to the ethnographic sensibility to the direct observation of action and interaction can allow work in the symbolic interactionist tradition to be liberated from a one-sided reliance on discursive and linguistic data.

\section{Affective Embodiment}

Attunement with others is by way of mirroring and mentalizing, which is deeply impacted by our affective architecture much like the construction and maintenance of our individual and collective biographies. Indeed, if we develop emotional signatures that shape our habits and dispositions, and if our self is inextricably linked to the individuals and groups we inhabit, then the projection of embodiment outwardly very likely syncs up and merges with others; and, therefore, becomes essential to how affective systems are expressed pre- or unconsciously as well as in conscious decisions regarding the types of expressive equipment we believe emulates who we are.

Indeed, Panksepp's (2005:170) own work suggests that bodily display of affective systems may be ubiquitous and unconscious. As such, it is not implausible to suggest that (1) many emotions have ubiquitous corresponding bodily displays (Witkower and Tracy 2018), and (2) some emotion displays also have localized vernaculars shaped by structural and cultural variation (Kemper, 2006). Fascinating new research puzzles emerge from these considerations, centered on the social origin and distribution of affective embodiment styles. Do specific groups or classes of individuals have habituated affective styles based on the emotion biographies? That is, do communities that have experienced intense FEAR and SEEKING due to refugee status also develop distinctive affective bodily displays? Are they able to empathize with others who display these affective systems vis-à-vis other ones? Put differently, does embodiment, attunement, and empathy become delimited based on how deeply carved out some affective systems are in a group? In essence, if language can delimit the cognitive 
appraisal of situations (Heise, 1977), then it seems we could develop "dictionaries" of bodily display that high affective styles too (Özkarar-Gradwohl et al. 2014).

\section{Concluding Remarks}

This paper builds on the existing momentum of introducing neuro- and cognitive science to sociology; particularly social psychology. Panksepp's argument that affective systems instead of primary emotions should be the unit of analysis leveraged the evolutionary and neurological foundations of cognition more effectively was presented. SEEKING, RAGE, LUST, FEAR, GRIEF, CARE, and PLAY appear to have specific subcortical locations and neurochemical signatures, and therefore, present compelling evidence of central motivations that were key to human survival as they evolved across a range of ecological niches. Panksepp's point was that SEEKING-curiosity about one's environment or PLAY-socially encouraged interaction that bonds conspecifics and imparts important tasks-had evolutionary roots, but via learning experiences, what we seek or how we play is culturally specific; the motivation, however, is ubiquitous. Drawing from contemporary neuroscientific understanding of the relationship between affect and cognition, then, Panksepp argues these systems can be superordinate to cognitive functions; can command them; and can also work in tandem with cognitive functions.

Building on this foundation, and insights already present in sociology (Turner, 2000, 2007) and neurosociology (Franks, 2006, 2019), we argued that because affective systems consist of neuronal channels that deepen when activated, interesting variations may be observable at the neuronal, individual, and social levels in which one or more system is more salient than others. This may be ephemeral or, more interestingly, a system may come to saturate the construction and maintenance of an autobiography or collective biography, and it may have consequences for how we project self, attune with others, and consciously or unconsciously do bodily language. In turning to embodiment, however, we were also able to consider some aspects of cognitive neuroscience that could contribute to ongoing work in neurosociology building on symbolic interactionism (Neimeyer, 2013; Kalkhoff et al., 2019).

In considering the embodied and projected self, for instance, we showed that, to date, work examining how and why embodied versus linguistic pathways converge and diverge could 
open up new insights into how the self develops or acquires behavioral repertoires. Ultimately, this paper set out to engage both the exciting work being done to bring brain science into dialogue with social psychology by suggesting supplemental elements that could push new boundaries in the future. 


\section{References}

Abrutyn, Seth. 2019. "Toward a General Theory of Anomie: The Social Psychology of Disintegration." European Journal of Sociology 60(1):109-136.

Aron, Arthur and Tracy McLaughlin-Volpe. 2001. "Including Others in the Self." Pp. 89-108 in Individual Self, Relational Self, Collective Self, edited by C. Sedikides and M. B. Brewer. Philadelphia: Psychology Press.

Asma, Stephen T. and Rami Gabriel. 2019. The Emotional Mind: The Affective Roots of Culture and Cognition. Cambridge: Harvard University Press.

Barber, Jennifer S., Yasamin Kusunoki, Heather Gatny, and Jamie Budnick. 2018. "The Dynamics of Intimate Partner Violence and the Risk of Pregnancy during the Transition to Adulthood." American Sociological Review 83(5):1020-47.

Barsalou, L. W., Niedenthal, P. M., Barbey, A. K., \& Ruppert, J. A. (2003). Social embodiment. Psychology of Learning and Motivation, 43, 43-92.

Berger, Joseph, Bernard P. Cohen and Morris Zelditch Jr. 1972. "Status Characteristics and Social Interaction." American Sociological Review 37(3):241-255.

Boehm, Christopher. 2018. Moral Origins: The Evolution of Virtue, Altruism, and Shame. New York: Basic Books.

Bowles, Samuel and Herbert Gintis. 2011. A Cooperative Species: Human Reciprocity and Its Evolution. Princeton: Princeton University Press.

Buckner, R. L., \& Carroll, D. C. 2007. Self-projection and the brain. Trends in Cognitive Sciences, 11(2), 49-57.

Burke, Peter J. 1991. "Identity Processes and Social Stress." American Sociological Review 56(6):836-849.

Burke, Peter J. and Jan E. Stets. 2009. Identity Theory. New York: Oxford University Press.

Clark, Candace. 1987. "Sympathy Biography and Sympathy Margin." American Journal of Sociology 93(2):290-321.

Cochrane, Tom. 2018. The Emotional Mind: A Control Theory of Affect States. Cambridge: Cambridge University Press.

Collins, Randall. 2004. Interaction Ritual Chains. Princeton: Princeton University Press.

Conway, Martin A. 2005. "Memory and the Self." Journal of Memory and Language 53:594-628.

Cozoline, Louis. 2014. The Neuroscience of Human Relationships. New York: Norton.

Damasio, Antonio. 1994. Descartes' Error: Emotion, Reason, and the Human Brain. New York: Avon Books.

Damasio, Antonio and Norman Geschwind. 1984. "The Neural Basis of Language." Annual review of neuroscience 7(1):127-147.

Davis, Kenneth L. and Christian Montag. 2019. "Selected Principles of Panskeppian Affective Neuroscience." Frontiers in Neuroscience 12:doi: 10.3389/fnins.2018.01025.

de Waal, Frans. 2019. Mama's Last Hug: Animal Emotions and What They Tell Us About Ourselves. New York: W.W. Norton.

Denzin, Norman K. 1985. "Emotion as Lived Experience." Symbolic Interaction 8(2):223-240.

Durkheim, Emile. 1912 [1995]. The Elementary Forms of Religious Life. Translated by K. E. Fields. New York: Free Press.

Durkheim, Emile and Marcel Mauss. 1967. Primitive Classification. Chicago: University of Chicago Press.

Ekman, Peter. 1982. Emotions in the Human Face. Cambridge: Cambridge University Press.

Emirbayer, Mustafa and Ann Mische. 1998. "What Is Agency?". American Journal of Sociology 103:962-1023.

Franks, David D. 2006. "The Neuroscience of Emotions." Pp. 38-62 in Handbook of the Sociology of Emotions, edited by J. E. Stets and J. H. Turner. New York: Springer.

---. 2019. Neurosociology: Fundamentals and Current Findings. New York: Springer.

Franks, David D. and Jonathan H. Turner, eds. 2013. Handbook of Neurosociology. New York: Springer. 
Frijda, Nico H. 1996. "Moods, Emotion Episodes, and Emotions." Pp. 381-403 in Handbook of Emotions, edited by M. Lewis, J. M. Haviland-Jones and L. F. Barrett. New York: Guilford Press.

Frye, Margaret. 2012. "Bright Futures in Malawi's New Dawn: Educational Aspirations as Assertions of Identity." AJS; American Journal of Sociology 117(6):1565-1624.

Gallagher, S. 2005. How the Body Shapes the Mind. Oxford: Oxford University Press.

Gallese, V., \& Goldman, A. 1998. Mirror neurons and the simulation theory of mind-reading. Trends in Cognitive Sciences, 2(12), 493-501.

Greene, J. D., R. B. Sommerville, L. E. Nystrom, J. M. Darley, and J. D. Cohen. 2001. “An fMRI Investigation of Emotional Engagement in Moral Judgment.” Science 293(5537):2105-8.

Goffman, Erving. 1967. Interaction Ritual: Essays on Face-to-Face Behavior. New York: Pantheon Books.

--- 1981. Forms of Talk. Philadelphia: University of Pennsylvania Press.

Heise, David. 1977. "Social Action as the Control of Affect." Behavioral Sciences 22(3):163-177.

Hitlin, S., \& Elder, G. H., Jr. (2007). Time, Self, and the Curiously Abstract Concept of Agency. Sociological Theory, 25(2), 170-191.

Hitlin, S., \& Johnson, M. K. (2015). Reconceptualizing Agency within the Life Course: The Power of Looking Ahead. American Journal of Sociology, 120(5), 1429-1472.

Hochschild, Arlie. 1983. The Managed Heart: Commercialization of Human Feeling. Berkeley: University of California Press.

Iacoboni, Marco. 2009. "Imitation, Empathy, and Mirron Neurons." Annual Reivew of Psychology 60(653-670).

Johnson, Cathryn. 1992. "The Emergence of the Emotional Self: A Developmental Theory." Symbolic Interaction 15(2):183-202.

Kalkhoff, Will, Joseph Dippong, and Stanford W. Gregory Jr. 2011. “The Biosociology of Solidarity.” Sociology Compass 5(10):936-48.

Kalkhoff, Will, David Melamed, Josh Pollock, Brennan Miller, Jon Overton, and Matthew Pfeiffer. 2019. "Cracking the Black Box: Capturing the Role of Expectation States in Status Processes." Social Psychology Quarterly 0190272519868988.

Kalkhoff, Will, Richard T. Serpe, Joshua Pollock, Brennan Miller, and Matthew Pfeiffer. 2016. "Neural Processing of Identity-Relevant Feedback." New Directions in Identity Theory and Research 195-238.

Kalkhoff, Will, Shane R. Thye, and Joshua Pollock. 2016. "Developments in Neurosociology." Sociology Compass 10(3):242-58.

Kemper, Theodore D. 2006. "Power and Status and the Power-Status Theory of Emotions." Pp. 87-113 in Handbook of the Sociology of Emotions, edited by J. E. Stets and J. H. Turner. New York: Springer.

Lareau, Annette. 2011. Unequal Childhoods: Class, Race, and Family Life. University of California Press.

Lawler, Edward J. 2001. "An Affect Theory of Social Exchange." American Journal of Sociology 107(2):321-352.

Lawler, Edward J., Shane Thye and Jeongkoo Yoon. 2009. Social Commitments in a Depersonalized World. New York: Russell Sage.

LeDoux, Joseph. 2000. "Cognitive-Emotional Interactions: Listening to the Brain." Pp. 129-155 in Cognitive Neuroscience of Emotion, edited by R. D. Lane and L. Nadel. New York: Oxford University Press.

Lende, Daniel H. and Greg Downey. 2012. The Encultured Brain: An Introduction to Neuroanthropology. The MIT Press.

Lents, Nathan H. 2016. Not So Different: Finding Human Nature in Animals. New York: Columbia University Press.

Lizardo, Omar. 2007. "Mirror Neurons," Collective Objects and the Problem of Transmission: Reconsidering Stephen Turner's Critique of Practice Theory. Journal for the Theory of Social Behaviour, 37(3), 319-350.

---. (2009). Is a "Special Psychology" of Practice Possible? Theory \& Psychology, 19(6), 713-727.

Lizardo, Omar and Jessical L. Collett. 2013. "Embarrassment and Social Organization: A Multiple Identities Model." Social Forces 92(1):353-75.

MacLean, Paul D. 1977. "The Triune Brain in Conflict." Psychotherapy and Psychosomatics 28:207-220.

Maryanski, Alexandra and Jonathan H. Turner. 1992. The Social Cage: Human Nature and the Evolution of Society. 
Stanford: Stanford University Press.

McCauley, Robert N. and William Bechtel. 2001. "Explanatory Pluralism and Heuristic Identity Theory."

Theory \& Psychology 11(6):736-60.

Mead, G.H. 1934. Mind, Self and Society: From the Standpoint of a Social Behaviorist, Edited by C. W. Morris. Chicago: The University of Chicago Press.

Merleau-Ponty, M. 1962. Phenomenology of Perception. New York: Routledge \& Kegan Paul.

Michaelian, Kourken. 2016. Mental Time Travel: Episodic Memory and Our Knowledge of the Personal Past. MIT Press.

Mische, Ann. 2009. Projects and Possibilities: Researching Futures in Action. Sociological Forum, 24(3), 694 704.

Montag, Christian and Jaak Panskepp. 2019. "Primal Emotional-Affective Expressive Fondations of Human Facial Expression." Motivation and Emotion 40(6):760-766.

Mullainathan, S., \& Shafir, E. (2013). Scarcity: Why Having Too Little Means So Much. Macmillan.

Müller-Pinzler, Laura, Sören Krach, Ulrike M. Krämer and Frieder M. Paulus. 2016. "The Social Neuroscience of Interpersonal Emotions." Current Topics in Behavioral Neuroscience 30:241-256.

Niemeyer, Richard E. 2013. "What Are the Neurological Foundations of Identities and Identity-Related Processes?: An Examination of How the Default Mode Network Relates to Identity Theory." Pp. 149-165 in Handbook of Neurosociology, edited by D. D. Franks and J. H. Turner. New York: Springer.

Nisbett, Richard E. and Timothy D. Wilson. 1977. "Telling More than We Can Know: Verbal Reports on Mental Processes." Psychological Review 84(3):231-59.

Owens, T. J., \& Samblanet, S. 2013. Self and Self-Concept. In J. DeLamater \& A. Ward (Eds.), Handbook of Social Psychology (pp. 225-249). Dordrecht: Springer Netherlands.

Özkarar-Gradwohl, F.G., J. Panksepp, F. İçöz, H. Çetinkaya, Köksal F., K. Davis and N. Scherler. 2014. "The Influence of Culture on Basic Affective Systems: The Comparison of Turkish and American Norms on the Affective Neuroscience Personality Scales." Culture and Brain 2(2):173-192.

Panksepp, Jaak. 1998. Affective Neuroscience: The Foundations of Human and Animal Emotions. Oxford: Oxford University Press.

---. 2005. "On the Embodied Neural Nature of Core Emotional Affects." Journal of Consciousness Studies 12(810):154-184.

Park, Hae-Jeong and Karl Friston. 2013. "Structural and Functional Brain Networks: From Connections to Cognition.” Science 342(6158):1238411.

Raichle, Marcus E. 2015. “The Brain's Default Mode Network.” Annual Review of Neuroscience 38:433-47.

Ridgeway, Cecilia L. 2006. "Expectation States Theory and Emotion." Pp. 374-367 in Handbook of the Sociology of Emotions, edited by J. E. Stets and J. H. Turner. New York: Springer.

Robinson, Dawn. T., Smith-Lovin, Lynn., \& Wisecup, A. K. 2006. Affect Control Theory. In J. E. Stets \& J. H. Turner (Eds.), Handbook of the Sociology of Emotions (pp. 179-202). Springer US Scheff, Thomas. 1988. "Shame and Conformity: The Deference Emotion System." American Sociological Review 53(3):395-406.

Rubin, David C. 2019. "Placing Autobiographical Memory in a General Memory Organization.” Pp. 6-27 in The organization and structure of autobiographical memory, edited by J. Mace. Oxford: Oxford University Press.

Ruiz-Junco, Natalia. 2017. “Advancing the Sociology of Empathy: A Proposal.” Symbolic Interaction 40(3):414435.

Sacks, H., Schegloff, E. A., \& Jefferson, G. 1978. A simplest systematics for the organization of turn taking for conversation. In J. Schenkein (Ed.), Studies in the organization of conversational interaction (pp. 7-55). New York: Academic Press.

Schacter, Daniel L., Donna Rose Addis, and Randy L. Buckner. 2007. "Remembering the Past to Imagine the Future: The Prospective Brain.” Nature Reviews. Neuroscience 8(9):657-61.

Schutz, Alfred. 1967. Phenomenology of the Social World. Translated by G. Walsh and F. Lehnert. Evanston: Northwestern University Press. 
Schwenkreis, P., El Tom, S., Ragert, P., Pleger, B., Tegenthoff, M., \& Dinse, H. R. 2007. Assessment of sensorimotor cortical representation asymmetries and motor skills in violin players. The European Journal of Neuroscience, 26(11), 3291-3302.

Shott, Susan. 1979. "Emotion and Social Life: A Symbolic Interactionist Analysis." American Journal of Sociology 84(6):1317-1334.

Smith, Christian. 2015. To flourish or destruct: a personalist theory of human goods, motivations, failure, and evil. Chicago: University of Chicago Press.

Spreng, R. N., Mar, R. A., \& Kim, A. S. N. 2009. The common neural basis of autobiographical memory, prospection, navigation, theory of mind, and the default mode: a quantitative meta-analysis. Journal of Cognitive Neuroscience, 21(3), 489-510.

Squire, Larry R. 2004. "Memory Systems of the Brain: A Brief History and Current Perspective." Neurobiology of Learning and Memory 82(3):171-77.

Stryker, Sheldon and Richard T. Serpe. 1982. "Commitment, Identity Salience, and Role Behavior: Theory and Research Example." Pp. 199-218 in Personality, Roles, and Social Behavior, edited by W. Ickes and E. S. Knowles. New York: Springer.

Summers-Effler, Erika. 2004. "Defensive Strategies: The Formation and Social Implications of Patterned Self-Destructive Behavior." Advances in Group Processes 21:309-325.

Summers-Effler, Erika, Justin Van Ness, and Christopher Hausmann. 2014. "Peeking in the Black Box Studying, Theorizing, and Representing the Micro-Foundations of Day-to-Day Interactions." Journal of Contemporary Ethnography 44 (4):450-79.

Sweet, Paige L. 2019. "The Sociology of Gaslighting." American Sociological Review 84(5):851-75.

Tavory, Iddo and Nina Eliasoph. 2013. "Coordinating Futures: Toward a Theory of Anticipation." The American Journal of Sociology 118(4):908-42.

Thagard, Paul. 2014. "The Self as a System of Multilevel Interacting Mechanisms." Philosophical Psychology 27(2):145-63.

Tomasello, Michael. 2019. "The Role of Roles in Uniquely Human Cognitions and Sociality." Journal for the Theory of Social Behaviour DOI: 10.1111/jtsb.12223.

Tracy, Jessica L. 2016. Pride: The Secret of Success. Boston: Mariner Books.

Tracy, Jessica L. and Daniel Randles. 2011. "Four Models of Basic Emotions." Emotion Review 3(4):397-405.

Turner, Jonathan H. 2000. On the Origins of Human Emotions: A Sociological Inquiry into the Evolution of Human Affect. Stanford: Stanford University Press.

---. 2006. "The State of Theorizing in Sociological Social Psychology: A Grand Theorist's View." Pp. 353-374 in Contemporary Social Psychological Theories, edited by P. J. Burke. Palo Alto, CA: Stanford University Press.

---. 2007. Human Emotions: A Sociological Theory. New York: Routledge.

---. 2010. Theoretical Principles of Sociology, Volume 2: Microdynamics. New York: Springer.

Turner, Jonathan H. and Richard Machalek. 2018. The New Evolutionary Sociology. New York: Routledge.

Turner, Jonathan H. and Alexandra Maryanski. 2009. On the Origins of Societies by Natural Selection. Boulder, CO: Paradigm.

Turner, Jonathan H. and Jan E. Stets. 2006. "Moral Emotions." Pp. 544-566 in Handbook on the Sociology of Emotions, edited by J. H. Turner and J. E. Stets. New York: Springer.

Uddin, L. Q., Iacoboni, M., Lange, C., \& Keenan, J. P. 2007. The self and social cognition: the role of cortical midline structures and mirror neurons. Trends in Cognitive Sciences, 11(4), 153-157.

van der Westhuizen, Donné and Mark Solms. 2015. "Basic Emotional Foundations of Social Dominance in Relation to Panksepp's Affective Taxonomy." Neuropsychoanalysis 17(1):19-37.

Van Overwalle, F., \& Baetens, K. 2009. Understanding others' actions and goals by mirror and mentalizing systems: a meta-analysis. NeuroImage, 48(3), 564-584.

Wacquant, Luis. 2015. For a sociology of flesh and blood. Qualitative Sociology, 38(1), 1-11. 
Waytz, A., \& Mitchell, J. P. 2011. Two Mechanisms for Simulating Other Minds: Dissociations Between Mirroring and Self-Projection. Current Directions in Psychological Science, 20(3), 197-200.

Weed, Emi A. and Lynn Smith-Lovin. 2016. "Theory in Sociology of Emotions." Pp. 411-434 in Handbook of Contemporary Sociological Theory, edited by S. Abrutyn. New York: Springer.

Wentworth, William M. and John Ryan. 1992. "Balancing Body, Mind and Culture: The Place of Emotion in Social Life." Social Perspectives on Emotion 1(1):25-46.

Wentworth, William M. and Darrell Yardley. 1994. "Deep Sociality: A Bioevolutionary Perspective on the Sociology of Human Emotions." in Social Perspectives on Emotion, edited by D. D. Franks, W. M. Wentworth and J. Ryan. Greenwich, CT: JAI Press.

Whitehouse, Harvey. 2004. Modes of Religiosity: A Cognitive Theory of Religious Transmission. New York: AltaMira Press.

Williams, L. E., Huang, J. Y., \& Bargh, J. A. 2009. The Scaffolded Mind: Higher mental processes are grounded in early experience of the physical world. European Journal of Social Psychology, 39(7), 1257-1267.

Witkower, Zachary and Jessica L. Tracy. 2018. "Bodily Communication of Emotion: Evidence from Extrafacial Behavioral Expressions and Available Coding Systems." Emotion Review 11(2):184-193. 